\title{
FUTURE MODELS MAY HAVE INFRA-RED SENSORS
}

\author{
take a taxi and go fishing \\ how do you like that? \\ visit canada \\ hey look, i see a big moose \\ cat's nose is twitching \\ why don't you ever go \\ to work and earn money? \\ invest your money here \\ why don't you try it yourself? \\ i'm on guard duty \\ with the armored car \\ could you give me a lift? \\ then we could buy some lunch \\ gentlemen, here comes lunch \\ there is all the food we want \\ just give me a microsecond \\ maybe you likee something \\ to eat while you wait \\ of course, of course, well, well \\ i'll prove it to you \\ you sir. who, me sir? \\ well sir, what is the verdict? \\ believe me \\ i've never seen my sheet \\ tell me again, i don't get it \\ sorry, hotee dogs all gone \\ a natural using wild game \\ one share of wildcat oil \\ don't cut me. i never \\ heard of wildcat oil \\ broken glass, drawn stars \\ fine, fine, you killed him
}


hold it officer, it's my duty

right behind the car sir

before anyone sees me

my pleasure, you know what they say

money talks. $i$ just don't understand

xylophone trills

another day like yesterday

we'll be in gravy

pardon me gentlemen

is there a bank

in the neighborhood?

you drove up from hillcrest?

TWO TOGE THER

i know behind the soot flame is yellow singing distracts me

plink plink plink

practical

exploratory

$$
\text { topology }
$$

fierce visions are lost

over there

slices of white light

on dry mountain

all for the first time

rain, rain, and rain again 